\title{
Impact of the Expressia Platform on a Child with Autism Spectrum Disorder: Case Study
}

\author{
Ana Amaral \\ Escola Superior de Educação \\ Politécnico de Castelo Branco \\ Castelo Branco, Portugal \\ anaamaral@epfundao.edu.pt
}

\author{
Henrique Gil \\ Age.Comm - Instituto Politécnico de \\ Castelo Branco \\ Castelo Branco, Portugal \\ hteixeiragil@ipcb.pt
}

\author{
Beatriz Machado \\ Escola Superior de Educação \\ Politécnico de Castelo Branco \\ Castelo Branco, Portugal \\ bea_machado13@hotmail.com
}

\author{
Filipe Có \\ Escola Superior de Educação \\ Politécnico de Castelo Branco \\ Castelo Branco, Portugal \\ filibania@gmail.com
}

\begin{abstract}
This research work has as its theme the Impact of the Expressia platform on a Child with Autism Disorder. More and more importance has been given to intervention using technological support tools for children with Autism Spectrum Disorder (AEP). With this work, it is intended to contribute to the reinforcement of intervention intervention using the Expressia tool in the (AEP).. The methodological part of this work is directed towards observation, study, description and finding solutions for the case of Orlanda (fictitious name) a 9year-old child with(AEP)., while using the Expressia tool. The work developed here intends to collaborate for a better reflection on the use of Expressia in children with(AEP)., so that each time more adequate and effective functions are achieved. Thus, and considering what was observed during the intervention, it can be mentioned that the use of this tool, in this student, improved her communication and learning skills.
\end{abstract}

Keywords-Alternative

communication,

cognitive stimulation.

\section{INTRODUCTION}

The researchers sought to understand the impact of the Expressia platform on a child with ASD, having carried out two sessions, with previously defined activities that met the child's needs and interests. This Platform is recent, having appeared in November 2020. PEA is characterized as a disturbance that alters the child's development, in three groups: social relationship, communication and flexibility. This triad, identified by [11], defines whether the child will be following an abnormal pattern of development and, in case there is a deficiency in only one of the areas, it may indicate a completely different cause.

In the autistic child, communication, as well as social development, is seriously disturbed. These difficulties are exacerbated by rigid patterns of behavior, obsessive interests and routines. Some authors refer that the origin of the word Autism is Greek, where Self means I/self and Ism means state or orientation (state in which an individual is centered on himself).
The first clinical presentations accepted as descriptions of autism were published by Kanner, an Austrian psychiatrist based in the United States, [10]. He studied eleven children (eight boys and three girls) children who manifested similar behavioral characteristics and believed that all children with autism had normal levels of intellectual development. This group of children had a normal physical appearance, but each child exhibited extreme isolation. Later, it was shown that autism is also frequently associated with speech disorders and motor or sensory impairments.

At the same time, in 1944, an Austrian psychiatrist and researcher, Hans Asperger, where he wrote the article "Autistic psychopathy in childhood". Asperger observed a group of children, where he found that the pattern of behavior and skills occurred preferentially in boys, that these children had severe social deficiencies - lack of empathy, low ability to make friends, one-sided conversation, intense focus on a subject of special interest and uncoordinated movements. Despite the apparent verbal precocity of his subjects, Asperger called the children he studied little teachers, due to their ability to describe a topic in detail. Because his articles were published in German and his main work in the wartime, his study received little attention and only in the 1980s, his name was recognized as one of the pioneers in the study of autism, due to the translation for English made by [11].

In this translation, the characteristics of the child with ASD go through the following domains:

Social domain: The autistic child has difficulties in socializing with others, presenting behaviors outside the usual patterns and with a tendency to isolate themselves.

Domain of language and communication: Difficulties are evident in all aspects of communication, that is, a child can have a good command of grammar and articulation of speech, but may have a strange intonation, there are repetitions or omission of pronouns and a literal understanding of speech.

Domain of thought and behavior: The child has difficulties in exhibiting behaviors, which end up becoming 
repetitive stereotypes and, in some individuals, an exaggerated reaction to any unexpected change in the routine.

[9] called the syndrome studied by Kanner, "Early autism" and also finds that the cases studied by Asperger covered a wide range of patients, with a high IQ, which means that even today autistics considered intelligent are diagnosed as Aspergeres and those described with the characteristics mentioned by Kanner are diagnosed as having "Kanner's Syndrome".

Biochemical investigations have been carried out with individuals with Autism Spectrum Disorders in which the role of neurotransmitters is highlighted [5]. This author adds that one of the biochemical anomalies that has been reported for the longest time is related to the level of serotonin that is produced in the body during the metabolization of tryptophan and is necessary for the normal functioning of the brain [5]. The elevated level of serotonin in platelets is thus the most consistent finding in PEA [4].

Although the relationship between serotonin levels and autism-specific symptoms has yet to be clarified, several studies have proven that about $1 / 3$ of autistic individuals have hyperseretonin (Anderson, 1987 cited by [5].

\section{THEORETICAL FRAMEWORK}

\section{A. Contributions from Neurosciences}

As [12] states: "the idea that human language is a real window for brain/mind investigations arises with the emergence of Cognitive Sciences in the second half of the 20th century. The linguistic paradigms that, despite having different references, develop theoretical and methodological means to explain the functioning of language in the brain have contributed, in a decisive way, to this development".

In the study of the relationship between language and the brain, the use of new imaging technologies is evident, namely functional magnetic resonance imaging (FMRI), magnetoencephalography (MEG), positron emission tomography (Pet Scan), spectroscopy infrared (NIRS), among others, which serve to investigate how our brain works, namely in phonetics, reading and speech processing.

The areas that developed the most in this context, according to [12] were: Speech perception and recognition of spoken language, representation and word processing, and speech processing. The use of language neurosciences aims to identify the area of the brain responsible for each function of the mind.

According to the scheme of the Austrian Franz Gall (1757-1828), cited by [12], the language would be located in the frontal lobes, close to the eyes. He presented clinical evidence results from cases of speech loss after frontal lobe injuries, confirming what he thought he demonstrated with craniometry.

According to [12], neurosciences can enable the teacher to be better able to understand the learning difficulties in different types of students. On the other hand, they can be used to improve the choice of teaching materials that will facilitate the learning process. This branch of cognitive sciences, when applied to teaching, has an added value in learning to read or in the speed of the ability to acquire knowledge.

\section{B. Alternative Communication}

Communication is extremely important for any individual, it is through it that we express wishes, desires, feelings and opinions in relation to everything around us, thus interacting with others, from whom we expect communicative feedback. How to do it, then, when someone cannot communicate through speech? Completing or minimizing this limitation in terms of language and communication is the main purpose of Alternative Communication which, through the use of various communication systems and software, provides children or individuals with these limitations, situations of interaction and learning, giving them give them the opportunity to verbalize their thinking and actively build their knowledge.

[7] and [8] state that "additional and alternative communication is multimodal and children with complex communication needs should be encouraged to use all possible forms of communication to express their basic needs, wants and desires."

Second [2] alternative communication can be defined as follows:

Alternative communication is any form of communication other than speech and used by an individual in face-to-face communication contexts. Gestural and graphic signs, Morse code, writing, etc., are alternative forms of communication for individuals who lack the ability to speak. Alternative communication is that "it acts as a tool for communication in the popular field, without leaving aside social militancy, implying that journalists and/or communicators must be in the conflict, always with a clear tendency to democratize the word and the information", as defended by the Foro Medios Alternativos, cited by [9]. (p.4)

In Argentina, in 2002, the Cono Sur News Collective was created, and it is mentioned that through the internet it is possible to create alternative communication projects in distant places around the globe. With this, knowledge and skills are enriched through the exchange of experiences obtained through this communication. The newspaper Cono Sur states that "Alternative communication projects have the task of acting as facilitators of community development, building bonds and making common the experiences and knowledge of the different protagonists of social happenings." (p.13)

\section{Cognitive Stimulation}

Cognitive stimulation includes all activities that are aimed at maintaining or improving cognitive functioning in general, through exercises in memory, perception, attention, concentration, language, executive functions, spatial vision functions, etc.

According to [1] cognitive stimulation is of accentuated relevance and is reflected both in the child's general development and in their learning. It is important to stimulate the child and propose strategies that allow him to take advantage of this stimulation, thus contributing to a healthy and progressive development. (p. 41983).

[1] states the following in the Brazilian Journal of Development: "The stimulation of cognitive factors, especially in early childhood, will contribute not only to learning but also to the child's overall development, in addition to the influences of the family, social and cultural 
environment on development of school skills." (p. 4198841989)

It is intended with cognitive stimulation, to induce the development of emotional abilities, reasoning, memory, language, among others in order to allow the child to obtain satisfactory results in their personal and school life.

\section{Digital Platform: Expressia}

Expressia is only a few months old. However, the alternative communication and cognitive stimulation tool has already shown its effectiveness in many users. Launched in November 2020, in Brazil, it already has several users and professionals in rehabilitation and inclusive education who use it in their daily lives. Each one with their own knowledge and skills, providing inclusion and welcoming to people with disabilities.

Alternative communication emerges as a facilitating resource for the development of communication in children or young people who do not speak or who have limitations at this level, whether temporary or permanent. This resource can be used as a complement or supplement to speech, serving as support, depending on each particular case. This tool helps professionals in rehabilitation or special education, being a great facilitator for assistance, as it provides moments of interactivity and development of skills in terms of communication.

With regard to cognitive stimulation, users of the Expressia tool have access to numerous activities that promote cognitive stimulation, namely the development of concentration, sequencing stories, or simply everyday gestures.

Through this tool, we can also create our own activities, depending on the themes we want to address, using images selected by the user, such as the introduction of their own voice to emphasize that illustration, this aspect makes up for the fact that some words are from the tool to come from Brazil. Thus, intending to develop the cognitive abilities that are adequate to the public with which one is working.

The tool helps the interaction of children, young people, adults or even elderly people with disabilities, syndromes or various deficits (Autism, Cerebral Palsy, Trisomy 21, among others) with the use of communication boards for alternative communication and cognitive stimulation.

Expressia is accessible free of charge, via computer or smartphone. Expressia offers viable solutions for people who have difficulties in their verbalization through alternative communication, it also allows us to create interactive communication boards that relate images and sounds, symbols, colors, numerals, etc. This platform can be essential in day-to-day communication and interaction, facilitating simple tasks and providing more autonomy to its users. In Expressia you can insert your own voice or search for images on the internet to add to the communication boards, all according to the purpose of use.

This platform has a blog where there are several articles on current topics and also related to the Expressia Platform. Some of the themes we can find:

- Teleservice in Inclusive Education

- Cognitive Stimulation in the treatment of Alzheimer's
- Cognitive Stimulation in the treatment of autism

Access to the blog through: https://blog.expressia.life/

Figure 1 shows the example of the Expressia platform:

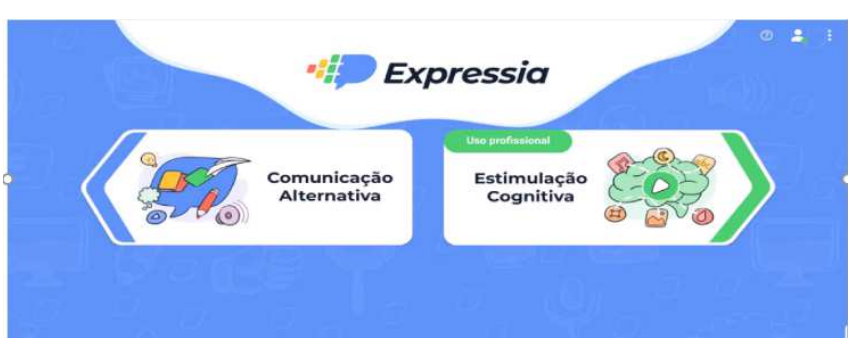

Fig. 1. Example of the Expressia platform.

\section{METHODOLOGY}

\section{A. Relevance of the study}

This study is considered pertinent, since research on intervention using the Expressia platform in PEA is still limited and aims to enhance the work carried out by Special Education teachers, as well as the benefits that such an action has on the development of children with this problem.

\section{B. Research Question}

Is the plataform Expressia able to intervene in improving communication in a child with Autism Spectrum Disorder?

\section{Aims of the research}

This investigation aims to understand and analyze the degree of satisfaction and ease of use of the Expressia instrument in a child with ASD, during two sessions. Such as, promoting cognitive stimulation and alternative communication by proposing activities that meet their interests and difficulties. And finally, register the activities developed by the child, concomitantly, the ability to communicate and get involved in the activities.

\section{Methodology}

In preparing this study and taking into account the proposed objectives, the methodological option to be used in this case study has an exploratory qualitative character, that is, it is intended to observe the degree of satisfaction and evolution in the child's ability to communicate through this instrument. Exploratory research is the type of research carried out when the chosen topic is little explored, making it difficult to formulate and operationalize hypotheses.

Based on the child's Technical Pedagogical Report (RTP) (given by the mother), which contains universal and selective measures, intervention strategies were designed with the Expressia platform to develop skills and adapt the platform to the girl's needs and characteristics. For this purpose, the observations (field notes) of the visits made by the investigators during the sessions carried out were recorded.

\section{E. Study participant}

In this case study, we have a convenience sample, since the child involved in the study was chosen because he has ASD and lives close to the master's students and, in turn, has been granted authorization by the parents to carry out the study. 
The participant involved in the study fits into a convenience sample, consisting of a child with the fictitious name Orlanda with the following characteristics:

Orlanda is a 9 year old child who has PEA. She attends the 3rd year of schooling in a school in her village which is somewhat isolated in the district of Castelo Branco. Due to the social isolation where the child is inserted, it is not possible to carry out constant monitoring by the Special Education teachers, which partially hinders their evolution and progress.

She is not very communicative, a typical characteristic of this disorder and presents difficulties in communication and social interaction. She has difficulties in expressing her feelings and emotions. At school, she does not participate in group activities despite the constant work of professionals.

She presents preferences in the topic related to studies of the solar system. As for the greatest difficulties are felt in terms of verbal expression, spelling and reading.

When put to work with the Expressia tool, Orlanda realized that they could express themselves more effectively through alternative communication, using Expressia to communicate with others.

Figure 2 illustrates the child interacting with Expressia:

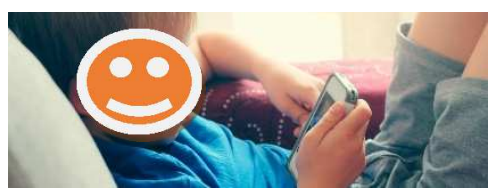

Fig. 2. Example of a child interacting with the Expressia plafform.

\section{F. Data Collection Methods}

As stated [3] "(...) data can be collected in different ways from the subjects. It is up to the researcher to determine the type of measurement instrument that suits the objective of the study, the research questions posed and the formulated hypotheses". Having taken these factors into account, the privileged instrument as an instrument for collecting information to be used, took the form of a record of field notes of the observations made during the sessions held by the master's students.

\section{RESULTS PRESENTATION}

In the observations made during two sessions in which the child used the Expressia tool, it was verified that there was a gradual increase in Orlanda's interest and interaction with the platform. In other words, at the beginning of the session, he revealed to be a shy, reserved child, not very communicative, lacking in initiative and not very empathetic. However, as the second session progressed, the child showed more commitment. This was also due to the ease of use of the tool and its initiative to download the application to your mobile phone and tablet. And make use of it in the context of the classroom, recess, school cafeteria and in the family environment. In the second session, some of the activities proposed during the first session were repeated, as well as new tasks were applied, in which Orlando improved their attention, commitment and, in turn, the learning of new concepts.

The activities proposed to the child were as follows:
- Alternative communication: We asked what she wanted for dinner, and through Expressia, she gave us her answer based on the images on the screen;

- Cognitive stimulation: answered questions about the solar system and later completed rhymes based on the illustrated images;

At the end of the sessions, we can conclude that the child has improved their communication skills, as well as their ability to learn with the topics covered. She gradually became involved with enthusiasm and joy in activities that met her preferences and needs.

As for the recording of observations, the researchers: considered that this tool can be an asset in the teachinglearning process of this child, as it improved their skills in terms of communication and concept learning. It was intended to give the child the possibility to communicate autonomously, using this means, thus improving their selfesteem and, in turn, their happiness.

TABLE I. FIELD NOTES SESSIONS

\begin{tabular}{|c|c|c|c|}
\hline \multicolumn{3}{|c|}{ Observations } \\
\hline 1st Session & \multicolumn{2}{c|}{ 2nd Session } \\
\hline Session start & End of session & Session start & $\begin{array}{c}\text { Endo f } \\
\text { session }\end{array}$ \\
\hline $\begin{array}{c}\text { Does not } \\
\text { communicate }\end{array}$ & $\begin{array}{c}\text { Communicates } \\
\text { little }\end{array}$ & $\begin{array}{c}\text { Communicates } \\
\text { when asked }\end{array}$ & $\begin{array}{c}\text { Ask } \\
\text { questions }\end{array}$ \\
\hline $\begin{array}{c}\text { Not very } \\
\text { empathetic }\end{array}$ & Smile a little & Smile & Smile \\
\hline $\begin{array}{c}\text { Not } \\
\text { interested }\end{array}$ & More interested & $\begin{array}{c}\text { Very } \\
\text { interested }\end{array}$ & $\begin{array}{c}\text { Very } \\
\text { interested }\end{array}$ \\
\hline
\end{tabular}

It is essential that people with difficulties that limit their communication capacity can have access to platforms that allow them to work with alternative communication and cognitive stimulation, improving their quality of life. It is crucial that children with communication difficulties are able to express their feelings.

In this study, it was intended to respond to the disturbance (AEP), thus responding to the child's needs. It was also found that there was an improvement in skills related to communication and child learning. However, we believe that for more reliable results it would be necessary to repeat the number of sessions for a longer time, so that the results could be even more consistent and reliable.

It is important that parents and educators reflect on how they transmit knowledge and knowledge, as not all children learn in the same way and with the same methods.

\section{CONCLUSION}

This tool allows you to stimulate the child, in the interaction with technologies, and benefit from the time on the mobile phone/tablet/computer with something that is functional, stimulating and that promotes learning. It's easy to use and being downloaded to your computer or mobile phone it can be accessible for everyone.

Since the beginning of the pandemic, the use of Expressia has been increasing, as it is a tool that works not only with cognitive stimulation, but also with alternative communication. 
In this case study, a didactic tool was shown with satisfactory results in a 9-year-old child with ASD, located in an underdeveloped rural area and attending the 3rd year of schooling. With the results obtained in our case study, we can refer that cognitive stimulation and alternative communication is important and contributes to children's learning, as well as to their performance and school success.

The importance of this type of technologies in the school environment should be mentioned, as they enhance access to the curriculum through differentiated and individualized strategies, which allow the true inclusion and participation of students in this school environment.

The Expressia Platform enables the materialization of pedagogical contents and objectives and improves the motivation for learning theoretical and practical contents.

\section{REFERENCES}

[1] Cavalcante, M., Lúcio. I, Vieira.A, Bittencourt.I, Vieira.D, Barbosa.L,Caldas.A e Davino.C. Davino.C. Estimulação cognitiva e aprendizagem infantil: revisão de literatura, in Brazilian Journal of Development Braz. J. of Develop., Curitiba, v. 6, n. 6, , jun, 2020, pp.41981-41990.

[2] Follin-Arbelet, A. "Perceção dos profissionais acerca do uso da comunicação aumentativa e alternativa com crianças com patologia neuromotora", 2017.

[3] Fortin, Marie-Fabienne - O processo de investigação: da concepção à realização. $2^{\mathrm{a}}$ ed. Loures: Lusociência, 1999.
[4] Gadia, C. A., Tuchman, R. and Rotta, N. T.. Autismo e doenças invasivas de desenvolvimento. Jornal de Pediatria, 80 (2), 83-94, 2000.

[5] Marques, C. "Perturbações do Espectro do Autismo: Ensaio de uma Intervenção Construtivista e Desenvolvimentista com Mães". 2000.

[6] Moraes, D. Comunicação alternativa, redes virtuais e ativismo: avanços e dilemas,inRevista de Economía Política de las Tecnologías de la Información y Romski Comunicación www.eptic.com.br, vol. IX, n. 2, mayo - ago, 2007.

[7] Romski, M. Augmentative Communication and Early Intervention Myths and Realities, in Infants \& Young Children Vol. 18, No. 3, 2005, pp. 174-185.

[8] Romski, M. A., al. A continuum of AAC language intervention strategies for beginning communicators. In: Reichle, J., Beukelman, D. R. \& Light, J. C. Exemplary practices for beginning communicators: implications for AAC. Baltimore: Paul H. Brookes, 2002.

[9] Telmo, I. "A integração das crianças com autismo nos estabelecimentos de ensino regular : realidade ou mito?". In: Educação especial e reabilitação. - Vol. 1, n 3, pp. 41-45, 1990.

[10] Kanner, L. Autistic disturbances of affective contact. Nerv. Child.; v. 2, 1942, p. 217-250.

[11] Wing, L. Aspects of Autism: Biological Research (editora), 1988.

[12] Henriques, A. As Neurociências ao Serviço da linguagem, Centro de Estudos em Educação, Tecnologias e Saúde. Instituto Politécnico de Viseu. 2013. 